
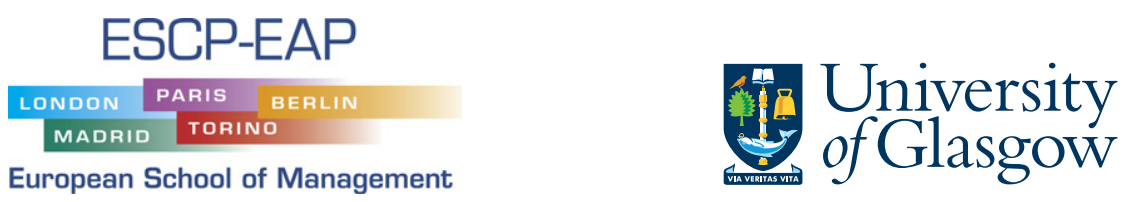

journal homepage: www.elsevier.com/locate/emj

\title{
HRM systems for successful information technology implementation: evidence from three case studies
}

\author{
Tanya V. Bondarouk ${ }^{\mathrm{a}, *}$, Huub J.M. Ruël ${ }^{\mathrm{b}}$ \\ ${ }^{a} H R M$, University of Twente, P.O.Box 217, 7500 AE Enschede, The Netherlands \\ ${ }^{\mathrm{b}}$ International Management, University of Twente, P.O.Box 217, 7500 AE Enschede, The Netherlands
}

\author{
KEYWORDS \\ HRM Strategies; \\ Information Technology \\ Implementation; \\ HR practices; \\ IT management
}

\begin{abstract}
Summary The success of information technology (IT) projects is highly dependent upon the end-users' behaviour. Whether end-users are able and willing to work with newly introduced software applications is fundamental. Hence, a key issue is supporting targeted employees of newly introduced software applications in their proper utilisation. HRM practices have the potential to provide such support. This article elaborates on HRM systems for software implementation focused on three HRM domains: ensuring employees are able to operate the new IT, providing opportunities to work with a new $\mathrm{IT}$, and removing obstacles to its use. Based on findings from 83 interviews conducted in three exploratory case studies, we specify 17 HRM practices that should be included in the agendas of IT projects if they are to achieve appropriate and committed use of newly introduced IT by the targeted employees.

(c) 2008 Elsevier Ltd. All rights reserved.
\end{abstract}

\section{Introduction}

IT projects are widely recognised as unstable and contradictory organisational developments that demand a range of technical and social changes. Bondarouk and Looise (2005) observe that the project team is forced to deal with various complicating circumstances surrounding IT implementation, including budget limitations, political games in the company, agreements with consultancy firms/suppliers, availability of resources/reallocating resources, job task analysis, employees' training, piloting the technology, and adapting it to a technological infrastructure. This article

\footnotetext{
* Corresponding author. Tel.: +31 5348936 66/35 19; fax: +3153 4892159.

E-mail addresses: t.bondarouk@utwente.nl (T.V. Bondarouk), h.j.m.ruel@utwente.nl (H.J.M. Ruël).
}

argues that strategic shaping of the HRM system, orienting it towards stimulating appropriate and committed use of IT by the targeted employees, has a great potential to overcome those complicating circumstances.

For years, academic researchers have been presenting empirical evidence showing that IT implementation success depends to a large extent upon social practices within IT projects, not just on technical issues (Bondarouk, 2006; Ciborra, 1999; Orlikowski, 1992; Robey et al., 2000). Although some studies mention the importance of certain HRM practices for IT projects (Ambrose et al., 1998; Ferrat et al., 2005; Jordan and Whiteley, 1994; Schell, 1998; Niederman and Mandviwalla, 2004), they do not see HRM issues as critical in IT implementation. For example, Brancheau et al. (1996), report that HRM was ranked ninth in order of importance by IT managers. Claver et al. (2000) found 
that HRM was a key topic in just $4.2 \%$ of management information system articles in the period 1981-1997. This reflects not only the lack of interest in and awareness of the significance of HRM for IT projects, but also the fragmentation within HRM when it comes to IT research.

This article goes a step further and examines the entire HRM system's influence on the success of IT implementation instead of only considering a range of distinct practices. The goal is to describe an HRM system that can lead to IT implementation success. Success in IT implementation is understood as achieving the desired IT users' work with IT. This involves the targeted employees appropriating a newly introduced IT and becoming committed to working with it.

We start broadly with ideas from the spectrum of literature on the management of IT projects. We then hone in on the role of HRM in IT implementation by building on the arguments of Lepak et al. (2006) and propose an HRM system for IT implementation that aims to reinforce success. In other words, a system oriented towards influencing the targeted employees' knowledge and skills in IT use (abilities), providing opportunities that allow them to work with and learn the given technology (opportunities), and motivating them by removing obstacles (motivation). We explore this three-prong HRM system in three case studies. Based on the evidence taken from 83 interviews, we analyse our findings and draw up a list of 17 specific HRM practices that support IT implementation success, and justify the necessity to intervene with HRM practices in IT projects.

\section{Managing IT implementation projects}

Nowadays, with the rise of wireless, mobile, internet, ERP and other technologies as well as integrated office environments, the distinction between specific names of complex standard software packages has become blurred. Our article concerns any IT package that facilitates the integrated, automated transmission of logistic, administrative, or financial processes. Usually such packages aim to enable organizations to achieve a variety of benefits such as faster administrative cycles, cost efficiency, reduced throughput times, standardised ways of working, and improved communication with external and internal customers and suppliers. From our perspective it is not the extent to which a planned IT package can be classified along traditional IT terms that is relevant, but whether it aims to create strategic value and contribute to the organization's performance- at which point HRM specialists could be involved in its implementation. Therefore, our approach is less relevant for standalone narrow-focused software applications.

We follow Klein et al. (2001) in defining IT implementation as the adoption of software during the transition period between its technical installation and its committed and task-consistent use by the targeted employees.

Earlier studies on managing IT implementation projects suggest numerous activities and practices that might ensure success: job reassignment or elimination (Klein et al., 2001); the provision of technical assistance to the users on a just-in-time basis (Rivard, 1987); rewards such as promotions, praise from supervisors, and improved working condi- tions (Meyers et al., 1999; Rousseau, 1989); effective communication regarding the reasons for IT introduction (Cooper, 1999; Pinto, 1998; Ruël, 2001); the provision of time for users to experiment with the new IT (Martinez, 1994; Zuboff, 1988); and the proactive shaping of IT values (Jarvenpaa and Leidner, 1998; Leidner and Kayworth, 2006; Tomlin, 1991). Much attention has also been paid to the quality and quantity of efforts to train employees in the use of a new system (Fleischer et al., 1987; Klein and Ralls, 1997; Marler et al., 2006). The argument is that ignoring these issues might result in the failure of a project.

Management is supposed to rationally implement practices that will ensure success in the IT implementation. End-users are supposed to work happily with the IT towards a promised growth in organisational performance. If users are resistant to change or less happy than expected, the difficulty could be due to mistakes made in the design process, 'wrong' age and 'wrong' subjective norms or behavioural control, insufficient experience with software, lack of support, low user participation, training mistakes, diverse compatibility beliefs or individual differences in cognitive absorptions (Agarwal and Karahanna, 2000; Benbasat and Taylor, 1978; Davis, 1989; Doll and Torkzadeh, 1990; Karahanna et al., 2006; King and He, 2006; Lu et al., 2001; Pavlou and Fygenson, 2006; Snitkin and King, 1986; Taylor, 2004; Venkatesh, 2000). In general, implementation is seen as a rational process, with predictable and analysable difficulties that can be avoided if the IT project is managed well. This approach has many attractive features that explain its wide adoption: it elicits key dimensions of failure situations across organisational settings, is straightforward to replicate and validate, and easy to develop prescriptions from.

Although we recognise the importance and convenience of many of the explanations and solutions offered by the traditional approach to IT research, we find two serious shortcomings. The first is theoretical, related to the fact that each of the IT studies describes a different set of practices; as a result, the literature is rich and varied but produces a confusing picture of the determinants of success. The influence of the determinants seems to become cumulative - the more the better. Perhaps as a result, there is a second and practical deficiency, one that has existed for several decades: the implementation of an IT is not as successful as predicted!

We argue for an approach that elicits key organisational dimensions that reinforce the desired IT use by employees and also reflects the dynamic character of its implementation. We base our subsequent arguments on the literature on human resource management.

\section{An HRM system for achieving the desired IT use}

HRM systems can be conceptualized along several levels: HR philosophy, policies, programs, practices and processes (Schuler, 1992); system architecture, policy alternatives and practices (Becker and Gerhart, 1996); or HR philosophy, HR policies, and HR practices (Lepak et al., 2004). Independent of the typology of such levels, the unique characteristic of HRM systems is that they encompass a collection of practices which should be internally consistent with the 
HR philosophy and business strategy, and thus support the reinforcing of desired organisational results and employees' behaviours (Lepak et al., 2006).

HR philosophies usually reflect

how an organization regards its human resources, what role the resources play in the overall success of the business, and how they are to be treated and managed. This statement is typically very general, thus allowing interpretation at more specific levels of action within an organization. (Schuler, 1992; p. 21)

HR policies are considered "statements providing guidelines for action on people-oriented business issues related to strategic needs" (Lepak et al., 2004; p. 643), while HR practices refer to specific organizational actions designed to achieve certain organizational outcomes (Lepak et al., 2006; p. 221).

By following the theoretical discussions of Lepak et al. (2006), we recognise three main domains through which HRM systems influence the desired employees' behaviour. Firstly, HR systems directly and indirectly affect the employees' motivation to perform by providing incentives and rewards. Secondly, HR systems directly influence the employees' abilities to perform by affecting their knowledge, skills, and abilities. Thirdly, HR academics suggest another dimension: opportunities for workers to perform. Even if employees have the attitude (motivation) and ability (skills), organizations must provide the opportunity to work and perform. Here, researchers emphasise the work structure and employees' involvement and empowerment.

Based on these arguments, we propose that the successful implementation of newly introduced IT is determined by its appropriate and committed use by the targeted employ- ees. The group of targeted employees in IT projects is usually very diverse and includes workforce employees, line managers, IT specialists, top management, and sometimes suppliers. In this study, by "targeted employees" we mean all organizational members involved in the implementation of IT. Further, the use of a newly introduced IT application by targeted employees should be valued, encouraged, rewarded, and anticipated by those responsible for the implementation project (Klein and Sorra, 1996).

Consistent with this logic, we propose that an HRM system oriented towards IT implementation covers three HR domains (Figure 1):

- HR policies and practices that remove obstacles to IT use and encourage employees to work with the IT (motivation);

- HR policies and practices that ensure employees' knowledge and build their skills to use the newly introduced IT (abilities);

- HR policies and practices that provide opportunities for employees to work with the newly introduced IT and encourage its use (opportunities).

Although the existence of three HRM domains is tangible, the challenging task remains of clarifying and translating those domains into concrete HR practices that are specific and successful in the IT implementation projects.

\section{Research methodology}

We conducted three explorative case studies to specify an HRM system that is appropriate for IT implementation and hence will encourage the desired users' behaviour. The goal

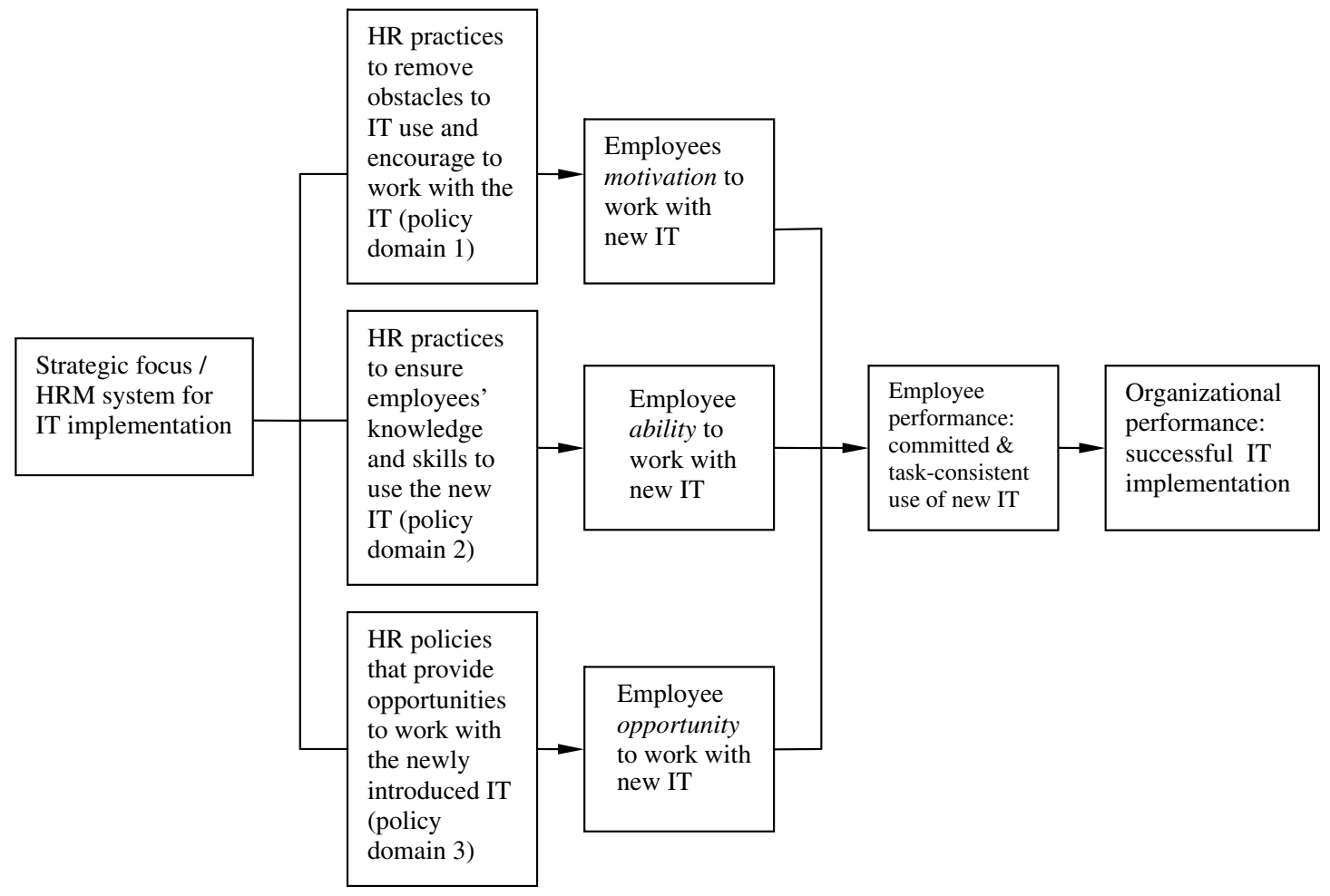

Figure 1 Research framework: HRM system for IT implementation 
of the case studies was to delineate the preliminary framework for HRM systems directed towards successful IT implementation.

The main criterion for case selection was a company that had recently introduced IT. From March-December 2002 we conducted nine micro-cases in different organisations: two insurance companies, two software design companies, two governmental organisations, a bank, a hospital, and a university. The objectives of the micro-cases were to explore their relevancy to our research, to understand how the research should be conducted, and to estimate the transparency of the resources including the unconstrained availability of end-users. Three organisations were selected for further analysis: a hospital, an insurance company, and a university (Medinet, InsurOrg and AcademCentre, respectively).

The case studies were based on qualitative methods: semi-structured interviews, field notes and document analysis. We conducted 83 interviews (each lasting from $45 \mathrm{~min}$ utes to 2 hours - around 110 hours in total) with managerial employees responsible for strategic policymaking in the companies, members of the IT project teams, and end-users of the systems (see Appendix). All interviews were transcribed and verified by the interviewees. Table 1 shows the number of interviews conducted during the case studies.

The interview techniques used in this study are noteworthy: in order to understand the IT implementation and its HRM support, we aimed to obtain both consistency and diversity in the responses. Interviewers played active roles rather than simply being 'speaking questionnaires'. Questions were oriented towards encouraging diversity by active intervention, provocative statements, informal information exchange, and stimulating disagreements.

The interview questions were generally the same for all interviewees, with certain emphases added for different user groups. During conversations with members of the project team, for example, we additionally asked about project steering activities, its history, support provided to the endusers, project lessons learned, interconnection with other IT projects, and future plans. The end-users were questioned about their experiences with the technology, their thoughts and reflections on their actions, the ways project leaders communicated with them about their thoughts and exchanged their experiences, and the rewards provided for using the IT.

The data gathering at Medinet took 10 months, 8 months at InsurOrg, and 12 months at AcademCentre. Such lengthy engagements allowed us to gain an understanding of the ongoing development of the IT projects through informal daily conversations with the employees. This built trust between the 'researcher' and 'subject', and helped develop a common research language. Important information was obtained through participating in company meetings of the project teams and key users and in training workshops.

\section{HRM practices for the Beaufort implementation at Medinet}

Medinet, a large regional general hospital in the Netherlands, introduced a new information technology called Beaufort (ERP technology) in September 2000 to personnel and salary specialists from both centralised and various decentralised departments.

When Beaufort was introduced to the PSA (Personnel and Salary Administration) department in Medinet, there were no changes in the users' job tasks. Although initially it was not very easy to work with the system, the employees were prepared to invest time and effort to discover its possibilities

Table 1 Type and number of interviews conducted

\begin{tabular}{|c|c|c|c|}
\hline Job position & Case study & $\begin{array}{l}\text { Number of } \\
\text { interviews }\end{array}$ & Main responsibilities of interviewees \\
\hline \multirow[t]{4}{*}{ Policymakers } & Medinet & 3 & $\begin{array}{l}\text { Strategic policymaking in organisations, selecting } \\
\text { information systems }\end{array}$ \\
\hline & InsurOrg & 4 & \\
\hline & AcademCenter & 5 & \\
\hline & Total & 12 & \\
\hline \multirow[t]{4}{*}{ Members of IT project teams } & Medinet & 3 & $\begin{array}{l}\text { Steering the IT implementation, providing support for end- } \\
\text { users, performing help-desk duties, maintaining functional } \\
\text { and technical administration of the system and sometimes } \\
\text { analysing ongoing use of the system }\end{array}$ \\
\hline & InsurOrg & 2 & \\
\hline & AcademCenter & 4 & \\
\hline & Total & 9 & \\
\hline \multirow[t]{4}{*}{ End-users } & Medinet & 21 & $\begin{array}{l}\text { Working with the newly introduced technologies on a } \\
\text { daily basis }\end{array}$ \\
\hline & InsurOrg & 19 & \\
\hline & AcademCenter & 22 & \\
\hline & Total & 62 & \\
\hline Total & & 83 & \\
\hline
\end{tabular}


as they were convinced of its potential usefulness in their jobs. However, Beaufort brought many changes to the tasks of the decentralised users in the Medinet case study: greater responsibilities for secondary tasks, new content in those tasks, and the necessity to be highly interdependent with other unfamiliar users. They did not want to accept a sudden increase in the importance of tasks that were formerly considered boring (Bondarouk and Sikkel, 2005).

Comments to the users on their use or learning of the system from the project team took place only in negative emergencies: any mistakes made by the users were pointed out immediately and discussed. Sometimes the comments from the project team disappointed the PSA employees. There was no rewards scheme, and the users were not rewarded or acknowledged for their efforts in learning the new system. During the interviews they recalled that it could have been a better experience:

"I wish we were paid back for all our efforts we invested in understanding Beaufort"'.

"In my previous work place we had a lot of rewards when we were obliged to learn ... But now I don't know, I am confused..."

Six (of 18 participants) followed a four-day software course at the supplier's location followed by a special didactical course. This group formed a core for peer teaching within the department. In our interviews, they and the other centralised employees were positive about the systematic, well-prepared instructions provided for them by their colleagues and system experts. The contents of the sessions were mainly related to technical issues of the system, and the users expressed their concern at the lack of guidance related to the organisational issues of Beaufort such as its goals for Medinet and changes in approaches and tasks due to the IT. During the training sessions, all the 'learners' were provided with personal computers and could practise using Beaufort under an instructor's guidance. The learning opportunities for the decentralised users, however, were very different. For them, the main source of information about Beaufort was a one-hour instruction session provided by one of the specialists from the central department. The main content of this training was also related to technical issues of Beaufort. Users felt there was a lack of access to computers during the instruction sessions: a single computer was available on which the instructor demonstrated how to operate the system. The learners had to memorise the information and lacked opportunities to practise. The reading materials available included the general Beaufort manual provided by the supplier and a 'sub-manual' developed by the central personnel and salary department:

\footnotetext{
"In fact many people cannot work well without good instructions or help. It is always better to give attention to education as much as possible rather than leave people to sink or swim on their own, as occurred with us..."

"We were ready to learn, but nobody taught us. First of all we needed to learn new functional tasks instead of how to press the buttons..."
}

The PSA employees were strictly limited in their freedom to explore the system, and were led by the project managers in learning the system. The users were unable to make choices about participating in educational courses, peer guidance, frequency of use, or experimenting with the system at the beginning. They were not always informed about all the changes and processes in the project. The users expressed that they lacked basic information and felt they were only informed about the managerial decisions and did not participate in those discussions:

"Suddenly I was told to give lessons to members of PSA. I don't like it when you are just told to do this without your opinion being sought",

"They told us how to use the system, how the system thinks, but not why they decided to introduce the system. They were very excited themselves about the system and asked us to explore all its possibilities".

Their 'exercising' with the system was strictly planned and scheduled. However, taking the initiative was not forbidden: skilful and experienced employees decided to write manuals and arrange additional instruction sessions for their colleagues.

The decentralised users were not allowed to make any inputs without a double check by the PSA department and the project team. Comments taken from the interviews illustrate this:

"Once I tried to investigate some options in the sick leave administration module, this caused a lot of problems. After that we were forbidden to experiment with it'.

"Actually all our operations with the system are controlled. We cannot make any inputs without confirmation from the PSA department'.

Experimenting with Beaufort was forbidden because it could have resulted in financial chaos. Once, the manager from Department [A] decided to make inputs into the sick leave administration module by himself without the PSA control. The next day, when the PSA specialist started to process salaries for Department [A], she discovered that four employees from that department had accidentally been placed on long-term sick leave. This would have led to financial penalties for Medinet from the inspecting organisation. After that 'experiment', Department [A] was removed from the pilot programme. Below we quote from our interview with that manager:

"Our operational manager started to work with Beaufort. He called his 'coach' from the PSA to input the data, and everything seemed to work fine. However, after ten days, our manager left for a vacation and I had to do it myself. I first phoned the same person in the PSA, but she was away. I decided to input the data anyway because I did not have time to wait. The next day they discovered a lot of mistakes in the system and forbade us to use it again".

The project resulted in two contrary situations: the centralised salary department implemented Beaufort effectively, efficiently, and in accordance with the initial plan; the introduction of the same system to the personnel specialists in other departments failed. The project was halted with an unclear future.

After three months of working with Beaufort, employees of the central department characterized it as 'not difficult'. They noted that they no longer had problems working with Beaufort and operated the basic modules quite easily and 
quickly. They stated that the system was very helpful and advanced in supporting their tasks and believed that they could perform the documentation and administration procedures faster than with the previous system. Also, they appreciated that the system helped them communicate with their clients: during telephone calls it was sufficient to use a single screen, avoiding difficult paper-based searching processes. In contrast, the decentralized users were convinced that filling in paper forms was much easier than using Beaufort. They felt uncomfortable working with the system and were even 'afraid' of clicking the buttons without supervision and help. The HR managers felt that the system did not facilitate their existing tasks, but rather added new ones. They acknowledged the importance of Beaufort for salary administration, but did not find it essential that they participated.

\section{HRM system for the KennisNet implementation at InsurOrg}

The Dutch insurance company InsurOrg introduced its digital knowledge network - KennisNet (built on Lotus Notes) - in October 2001 to the non-life insurance product managers. KennisNet did not result in changes to their job tasks. However, the main goal of the system (building a team among the users) was not transferred to the level of the needs of the individual users. A lack of clarity about what kind of information to input and share, and with whom and why, reduced the job relevance of KennisNet according to the users.

The KennisNet project documents mention a rewards system to encourage use, but it was never developed and implemented in practice. Many users noted that they would have liked more feedback, comments, and tips from the project leaders on how to work with the system. None of the users could recall any such comments on their work with KennisNet; neither remarks nor rewards. We did not see any evaluation activities linked with the project; our research was effectively the first attempt to evaluate the IT innovation. All of the users claimed that they did not have enough time to work with KennisNet. Employees sensed there was insufficient time for optional activities such as operating and mastering the system. Their initial expectations had been that KennisNet would save time, but in practice they found that they had to invest more time. Managers did not specifically allocate time for discussions on KennisNet.

The employees acknowledged that if they had difficulties or questions, they usually sent e-mails to the project leader, and he definitely helped them. At the same time, the users commented that they did not notice much enthusiasm from the managers. Only the project manager kept on insisting, pressing, and requesting the users to make inputs in the system. However, as described earlier, the managers were not empowered to force the non-life insurance specialists to use the system:

"There was a mismatch between what the managers were asked to do, and what they really could do"'.

The immediate managers of the other specialists had a different attitude towards KennisNet: all of them knew about the system and probably about its objective, but they did not stimulate its use. The system seemed to be designed and introduced at the request and based on the ideas of the non-life insurance professionals. However, there was no investigation into their ideas before the installation of the system: into what kind of information they actually needed and for what purposes.

Before KennisNet was introduced, there was a workshop in which the specifications and functionalities of the system were introduced and clarified. The majority of the employees perceived this as sufficient and clear, although some noted that it was "not very intensive" and "could be better". It was the only formal training on KennisNet offered to the users. We found that some of them did not even remember this had occurred:

"As an introduction, I had two hours of instruction. It could have been better, I must say. I realise that better instructions and education would have helped more."

"We were trained at the beginning, but not very intensively. It was an overview of the possibilities in the system: you can do this and that.... Then, when we started our attempts to work with it. .."

The project leader composed a manual on how to work with KennisNet: it contained detailed information about the portal and the databank, and all items and applications. However, there was no description of the goals of the system, of work situations when it would be wise to use KennisNet (and its various items), of targeted groups of users and their information needs covered by the system, rules and recommendations on how to work with it (what to input, and when) and so on. Many users found the manual helpful; some noted that there was no need for a manual at all; others did not know or could not recall such a document.

All the interviewees emphasised that they were not restricted in their use of KennisNet. They were free to choose whether to use it, when to use it, and for what purpose. They could decide and plan all the actions undertaken with the system. However, some users noted that at the beginning there was a rule: all documents must be sent to the managers who would then make the inputs into the system. The employees even found this attractive - they did not "have troubles" with the system itself. The managers stressed the voluntary basis of the use of KennisNet. Officially, the employees did not need permission to publish documents in KennisNet. However, some felt that they had to discuss the content of the documents with their immediate manager before publishing them. It is possible that there was no encouragement for all information to become public across the five sub-companies.

The project failed despite the users' initial interest and perceived need for such a system. The targeted employees ceased working with it within two months of its introduction, and the project appeared to be almost beyond recovery. After six months, the users' frustration with the technology reached a level where they did not see any job relevance in KennisNet. The technology was perceived as useless: it did not support the execution of tasks in the non-life insurance group, the information published was not available in time, and it was out of date and did not cover specific or difficult issues concerning the non-life insurance information. 


\section{HRM system for the SAP_HR implementation at AcademCenter}

AcademCenter introduced the SAP_HR (ERP technology) to its personnel and salary administrators in 2002. Following its introduction, administrative personnel tasks had to be performed through SAP_HR, including employee appointments, modifications to basic information, payment information, working time registration, relocation processing, promotion, administration of leave (sabbatical, sick, parental) and the production of HR statistical reports (Bondarouk and Van Riemsdijk, 2007).

The users experienced significant changes in their daily tasks following the introduction of the SAP_HR system: greater responsibilities for making online inputs, stronger control over these inputs, the necessity to be interdependent and a need to collaborate across the members of the entire group, many of whom were strangers. Stress and uncertainty linked to making incorrect inputs to SAP_HR stimulated a negative interpretation of the technology among the users from the start: they did not want to invest a lot of effort and were disappointed with the technology. From the beginning, the users assumed that the system was not useful for their job tasks.

We did not discover any policies or arrangements for recognising progress in the use of the system. During the departmental meetings, they discussed "bad" cases in the use of SAP_HR - when employees did not get their salaries for instance. Reward schemes did not exist. In the units, the heads of the departments financially rewarded users for their troubles with SAP_HR on their own initiative. However, we did not discover initiatives to reward the users from the project team or from 'top' managers. Here are some of the users' comments:

"We never got any feedback from the SAP_HR project team - no encouraging comments, enthusiastic letters, or feedback notes during key-user meetings. No financial support for our troubles. But our direct boss, the head of the P\&O department in the faculty, paid us special bonuses to compensate for our hard work with SAP".

The interviewees expressed that communication with the management of the project had to be improved:

"At the beginning I was very frustrated - you complain 4-5 times about the same problem, and you don't see anybody working on it... Maybe they were, but without telling us. Anyway, communication has to be improved. I felt that if, following my request, the System Administrators went to the consultants, that the situation became blocked with an unclear future."

Sometimes they had to wait a long time to get an answer to a seemingly simple question. In such situations, some users preferred to call and ask a colleague from another unit rather than somebody from the project team. The users even questioned the level of professional qualifications of the functional administrative team of the system.

Before SAP_HR was introduced, there was a course about the system provided by the consultants. All interviewees felt that this was inadequate and did not give any idea about using SAP_HR. They recalled that they were instructed only how to click the buttons; no knowledge was communicated about the main principles of SAP and the outcomes of incorrect inputs. In some situations during the course, there was only one PC available for three learners. The content of the instructions seemed to be far removed from reality:

"During the first day of the course they explained to us how to click the buttons, but it was too simplistic. The second day was a bit better - about the administration of basic employee appointments. But, in reality, all the appointments include so many special details and different personal situations that when I came to do the work, I felt lost with my limited knowledge from the course."

There were many manuals and 'sub-manuals' about operating SAP_HR. The interviewees stated that they were not helpful: they were too long. Nobody could find time during their usual working days to study these "encyclopaedias". The first "good" manual was released on CD-ROM half a year after SAP_HR's introduction, and the best one, a year after the introduction. Both manuals were the joint product of the salary and personnel employees. Our document analysis has shown that there were about 40 manuals and sub-manuals. Employees in some units developed internal instructions. The users also received $2-5$ emails each week from the system administrators about small changes to the main manual. Some users printed them out and put them on their whiteboard and tried to memorise the contents, others ignored these notes, relying on the expertise of key users.

The interviewees emphasised that they did not even think about their own decision-making responsibilities during the SAP_HR implementation phase because the project was so complicated that they did not even know what kind of decisions they could make on their own. Nevertheless, all users were free to use SAP_HR; they could plan their work themselves and divide up their tasks. The most proactive department took a chance: they changed their working schedules during the early months, and their access hours for faculty employees were restricted, for the rest of the time they were busy with SAP_HR:

"We decided to close our P\&O department for three days in order to check all the paper files and find the mistakes in SAP_HR. We manually compared the paper- and SAP. based personnel data for all employees in the faculty, and found lots of errors in SAP".

\section{Many confirmed that they were}

"... completely free in working with SAP. [They] were not limited or controlled concerning [their] priorities on how to work or who was doing the transactions. [They] had freedom to create [their] own style of working."

The targeted employees believed that using the system did not help them execute or improve their task performance. Some functionalities in SAP_HR were considered useless, other important ones were lacking. Furthermore, the HRM administration logic did not match the SAP_HR logic: users had to change their way of submitting and processing the documents, SAP_HR did not accept inputs made immediately one after another, and transactions were blocked for two weeks after a single input. 


\section{Lessons learned: HRM practices for IT implementations}

Based on the findings from three case studies, we summarize the data in Table 2, where the main observations per case study are listed. This allows us to see in which ways the case studies stressed different HRM practices in IT projects.

The majority of the findings in Table 2 have a negative connotation: "no rewards" or "no compensation system". All three cases resulted in difficult implementations. The implementation of Beaufort at Medinet was frozen, the use of KennisNet at InsurOrg stopped after a couple of months, and the implementation of SAP_HR suffered from unanticipated complications for eight months.

Based on Table 2 we draw components for three categories in an HRM system for IT implementations: removing obstacles and strengthening motivation, building abilities, knowledge and skills, and providing opportunities.

Looking at the practices in three companies concerning removing obstacles and strengthening motivation, we notice that the importance of a specific reward system for learning and practicing with a new IT, and a need for regular evaluation rounds (feedback sessions) - were stressed in all cases. The Medinet and AcademCenter cases revealed the importance of the rewards and reorganization of the pay system for IT users. Users in Medinet were given special time to learn Beaufort, while in the AcademCenter users did not but did emphasize a need in creating time for learning the technology. Allocating special time is important for such projects. With different accents, respondents in all three cases sensed a lack of managers' time allocated for discussions, feedback, and providing help just-in-time. This highlights another dimension - the availability of managers' time for the users to discuss IT implementation issues. During the Beaufort implementation project managers scheduled special office-hours for questions and discussions, and employees had two hours of 'Beaufort practice' every morning - time when everybody was encouraged to experiment using stand-alone computers. Specially scheduled 'Beaufort coffee breaks' were designed to figure out 'best Beaufort practices' and discussing difficulties. During the KennisNet project we saw no such arrangements and heard users complain about the lack of time dedicated to the technology. In the AcademCentre some HR departments made decisions to schedule two dedicated hours each day for learning SAP_HR. Therefore, we stress the importance of time-allocation issues for learning a newly introduced technology. Observations from all case studies support earlier findings that show one of the main foundations for users' behaviour towards IT is its usefulness for their job tasks (Davis, 1989; Venkatesh, 2000). We add to these earlier findings by observing that before introducing a system, it is crucial to conceptualise its importance for the users and convince them of its relevance. Technology may have a high-level strategic goal; this must be modified, however, to the language and needs of the end-users, and therefore translated to the users' motives. For example, a system's mission to restructure a company will become visible, tangible, and relevant if it is broken down into sub-goals for the users, such as making their concrete tasks easier, improving the quality of report generation, and speeding up information searching. Thus, the usefulness of the technology should be personalized and clarified from the primary mission to concrete employees' needs. All in all, the analysis of the motivational factors has shown the importance of an integration of:

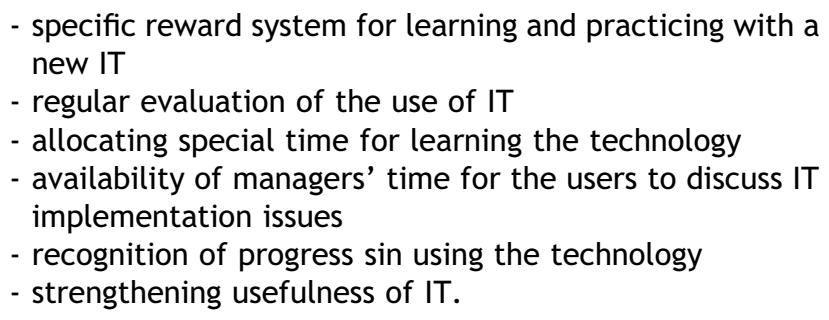

Analysing an HRM domain for building abilities, knowledge, and skills (Table 2), we observe that training and job needs analysis was not done in any of the three companies. The same held true for training sessions: they were not designed and oriented towards job tasks of the users. In all cases we saw applications of very standard, general manuals and other materials. Indeed, in the AcademCenter case, the contents of the SAP_HR training sessions were far from the reality of the personnel and salary tasks, and mostly oriented towards technological functionalities. Lack of clarity and uncertainty about the use of SAP_HR led the users to design their own manuals, sub-manuals, and short e-mail instructions. We conclude that only 'customised', user-centred learning opportunities will improve the users' behaviour. Users need task-based, job-related manuals and instruction sessions on why, when, and how they should use the various services (modules) in the system. Further, as follows from Table 2, the Medinet case study shows the importance of special regulations for new users: advanced users of Beaufort became peer instructors. At the same time, the InsurOrg case reveals the lack of arrangements for newcomers that led to low use of KennisNet by new users.

The analysis of the domain, 'building abilities, knowledge and skills' shows the importance of an integration of the following factors:

- analysis of users' training needs

- adequacy of training sessions in terms of their duration, depth, and breadth of coverage

- task-oriented training

- customized availability of resources to learn

- regulations to provide newcomers with training

- peer teaching/training.

Examining the practices in three companies concerning providing opportunities (Table 2), we see that users' participation and responsibility are critical for the IT implementation. Users of Beaufort and SAP_HR sensed a lack of freedom in defining their training needs for developing training sessions. They did not participate in designing manuals and instruction sessions. The employees of Medinet stressed the importance of their freedom to contact Beaufort suppliers directly instead of being limited only to the project team. SAP_HR users underlined the significance of their freedom to determine their working schedule in a way that 
Table 2 HRM practices for IT implementations: empirical findings

\begin{tabular}{|c|c|c|c|}
\hline \multicolumn{4}{|c|}{ Findings: HRM practices in IT implementation projects in three organizations } \\
\hline & $\begin{array}{l}\text { Removing obstacles and strengthening } \\
\text { motivation }\end{array}$ & Building abilities, knowledge and skills & Providing opportunities \\
\hline \multirow[t]{5}{*}{ Medinet } & $\begin{array}{l}\text { - No specific reward systems for learning } \\
\text { Beaufort }\end{array}$ & - No analysis of users' needs in training & $\begin{array}{l}\text { - Lack of freedom in using the IT: users were } \\
\text { led through most of the steps involved in } \\
\text { learning the system by the project managers }\end{array}$ \\
\hline & $\begin{array}{l}\text { - No reorganisation of the pay system or any } \\
\text { recognition records }\end{array}$ & $\begin{array}{l}\text { - Training was not oriented towards job tasks } \\
\text { to be performed via IT }\end{array}$ & $\begin{array}{l}\text { - Project team planned and scheduled all the } \\
\text { educational, experimentation and } \\
\text { implementation activities }\end{array}$ \\
\hline & $\begin{array}{l}\text { - Mistakes made by the users from the central } \\
\text { personnel and salary department were } \\
\text { immediately pointed out and discussed } \\
\text { during subsequent meetings }\end{array}$ & - Very standard software manuals & $\begin{array}{l}\text { - Users were not allowed to make inputs } \\
\text { without being double-checked by the project } \\
\text { team and PSA employees }\end{array}$ \\
\hline & $\begin{array}{l}\text { - Comments on use of the system occurred in } \\
\text { the event of negative emergencies }\end{array}$ & - Well-done peer training & $\begin{array}{l}\text { - No opportunities to experiment and } \\
\text { practise with IT }\end{array}$ \\
\hline & $\begin{array}{l}\text { - HR specialists did not initiate or participate } \\
\text { in reviewing the progress of employees } \\
\text { working with the new technology }\end{array}$ & - Well-done training for newcomers & $\begin{array}{l}\text { - The users did not have influence over the } \\
\text { training content }\end{array}$ \\
\hline \multirow[t]{7}{*}{ InsurOrg } & $\begin{array}{l}\text { - Reward system existed in documents but } \\
\text { was not applied in practice }\end{array}$ & $\begin{array}{l}\text { - Introductory workshop to all future users of } \\
\text { KennisNet }\end{array}$ & - The use of KennisNet was optional \\
\hline & $\begin{array}{l}\text { - Users desired feedback and comments on } \\
\text { their work with IT }\end{array}$ & $\begin{array}{l}\text { - Training needs were not analysed for the } \\
\text { instruction, therefore the quality of the } \\
\text { workshop was perceived differently among } \\
\text { the users }\end{array}$ & $\begin{array}{l}\text { - Users were free to plan their operations } \\
\text { with KennisNet }\end{array}$ \\
\hline & $\begin{array}{l}\text { - No evaluation of the project except this } \\
\text { research }\end{array}$ & $\begin{array}{l}\text { - Self-designed manual described technical } \\
\text { issues while failed to provide the conceptual } \\
\text { information about KennisNet }\end{array}$ & $\begin{array}{l}\text { - Publishing certain documents needed } \\
\text { special permission from the managers }\end{array}$ \\
\hline & $\begin{array}{l}\text { - Users perceived lack of time to operate } \\
\text { with KennisNet }\end{array}$ & & $\begin{array}{l}\text { - Lack of encouragement for making } \\
\text { information public }\end{array}$ \\
\hline & - No enthusiasm from managers about & & \\
\hline & KennisNet implementation & & \\
\hline & $\begin{array}{l}\text { - Managers were not empowered to request } \\
\text { using the technology }\end{array}$ & & \\
\hline \multirow[t]{4}{*}{ AcademCenter } & $\begin{array}{l}\text { - No specific reward systems for learning } \\
\text { SAP_HR }\end{array}$ & $\begin{array}{l}\text { - Standard course on using SAP_HR was } \\
\text { provided to all users }\end{array}$ & - The use of SAP_HR was obligatory \\
\hline & - No evaluation rounds & - No job needs analysis & $\begin{array}{l}\text { - Users were free to plan their work with the } \\
\text { technology }\end{array}$ \\
\hline & $\begin{array}{l}\text { - Only "bad" experiences were noticed by } \\
\text { the managers }\end{array}$ & $\begin{array}{l}\text { - Information overload: too many manuals } \\
\text { and other instructions on use of SAP_HR }\end{array}$ & $\begin{array}{l}\text { - Some departments re scheduled their } \\
\text { working hours to free some time for learning } \\
\text { the technology }\end{array}$ \\
\hline & - Great time pressure to learn the technology & & \\
\hline
\end{tabular}

- No evaluation of the project except this research

with KennisNet

- Managers were not empowered to request the technology

SAP HR

- Only "bad" experiences were noticed by

- Great time pressure to learn the technology 
Table 3 HRM system for IT implementation: HRM policy domains

HR policy domain "Removing obstacles and strengthening motivation":

- specific reward system for learning and practicing with a new IT

- regular evaluation of the use of IT

- allocating special time for learning the technology

- availability of managers' time for the users to discuss IT

implementation issues

- recognition of progress sin using the technology

- strengthening usefulness of IT

HR policy domain "Building abilities, knowledge and skills" - analysis of users' training needs

- adequacy of training sessions in terms of their duration, depth, breadth of coverage

- task-oriented training

- customized availability of resources to learn

- regulations to provide newcomers with training

- peer teaching / training

HR policy domain "Providing opportunities"

- define their training needs

- contribute to design manuals and training programs

- plan their work with IT

- contact IT suppliers

-re-schedule learning and training of IT

allowed them to combine IT learning activities and normal daily job tasks. In all cases employees stressed importance of their possibilities to re-schedule their work and learning with the new IT. The analysis of the domain 'providing opportunities' shows that it is important that users have the possibilities to:

- define their training needs

- contribute to design manuals and training programs

- plan their work with IT

- contact IT suppliers

- re-schedule learning and training of IT.

We summarise our discussions and empirical findings and list the $17 \mathrm{HRM}$ practices within three HR policy domains that build an HRM system for successful IT implementation (Table 3).

\section{Discussion}

We propose considering implementation success as the achievement of the desired users' behaviour, when the targeted employees have appropriated a given technology and are committed to working with it. We believe such behaviour is accomplished by strengthening the HRM system for IT implementation.

Given that IT project practices rarely take place in isolation, we follow Lepak et al. (2006) by stating that failure to consider the whole set of practices ignores the potential and important explanatory value of unmeasured practices. Some separate HR practices are already considered impor- tant for IT implementation, and it is likely that some similarities with the list of HR practices we present in this article can be found in other studies. For example, Vadapalli and Mone's (2000) study on integrated user participation structures in IT projects identified five practices important to steer IT projects: group composition, empowerment of users, adequacy of rewards system, training, and growth and development. Another example is the research done by Kuruppuarachchi et al. (2002) which also suggests organizational practices such as user participation, effective communication, skilled personnel, work environment, and project monitoring and control. Mumford (2000) proposed 34 separate practices such as selecting for breadth of expertise, defining job expectations, providing training, selecting managers, and developing rotational assignment programmes.

We argue that this article goes a step further and addresses a comprehensive HRM system that reinforces the desired use of IT by the targeted employees. In particular, we propose that rather than gathering together various practices ('the more the better'), organisations should adopt a more integrated approach to accomplishing the desired use of IT by the targeted employees. Different user groups are likely to have different tasks and objectives in working with the technology; identifying those tasks and objectives and linking them to the design of the HRM system might provide better results in IT implementation. We do not claim that the list of HRM policies and practices identified in this study will be a panacea for all implementations. We are convinced that an integration of policies makes a significant difference as it reinforces the users' shared perceptions of the importance of a newly introduced IT. This is the first novelty addressed in the article.

Second, whereas most attention is currently paid to narrow HRM instruments at the individual level such as selection, appraisal, and rewards, HR practices at the group and organizational levels are less supported and discussed (Chung, 1997). This keeps HRM professionals away from a deliberate positioning during the IT implementation, and thus from a long-awaited HRM strategic contribution. The model we suggest calls for strengthening the strategic position of HR specialists in organizations by offering them a systematic method of building an HRM system for IT projects.

Our third contribution is related to the fact that current studies do not identify those professionals who should be responsible for undertaking the various activities to enable IT projects. Rather, the literature implicitly attributes these activities to information systems specialists or to the project teams that are, in practice, largely composed of technical people. We claim, however, that HRM specialists should actively interfere in IT projects by creating an integration of $\mathrm{HR}$ policies and practices for IT implementations, and aligning them with the business strategy.

Our study also distinguishes and clarifies micro-level practices usually overlooked by IT and HRM researchers in IT implementation studies (not to mention practitioners!). Recognising the role of such 'forces' is crucial for a better comprehension of the complexity of the content of HRM systems for IT implementation and for establishing agendas for IT projects. 
The results of our study are preliminary but important. The 17 HRM practices are developed from an empirical exploration of three case studies. Thus, the stability of our findings is open to question, and we would encourage additional research that explicitly examines and statistically validates (or repudiates!) our findings. Special research questions might concern the relevance of the suggested HR practices for IT users other than employees, such as suppliers or customers ${ }^{1}$. Regarding the effect of the proposed practices on the users' perceptions of the importance of a given technology and their appropriate and committed use, there are several interrelated issues that require further investigation. As a start, however, the study needs to be replicated with another, larger sample.

Another limitation of our study is that it does not address the conflict and political issues related to IT implementation in organizations. A political analogy is well-known in IT research, and many authors argue that most decisions in the implementation process are ultimately political, as they involve complex decisions with uncertain outcomes and actors with conflicting views, often resolved through the exercise of power (Bloomfield et al., 1992; Dawson et al., 2000; McLoughlin et al., 2000; Badham et al., 2001; Fehse, 2002). As organising the implementation process requires the mobilisation of power resources, it would be interesting for a subsequent study to investigate the IT project's effectiveness in encouraging the active political behaviour displayed by the HR specialists in IT projects (influencing, forming alliances, engaging), as opposed to politically passive tactics that prevent the pursuit of project goals (avoiding conflict, image building).

\section{Conclusions}

This research began with the intention of describing an HRM system for IT implementation. Building our arguments on earlier research into HRM systems, we propose that HRM systems can influence IT implementation success through ensuring and strengthening three HR policy domains:

- Removing obstacles and motivating users through providing feedback and the time to take advantage of opportunities to learn the technology effectively.

- Ensuring employees have the abilities (knowledge and skills) required to use a newly introduced IT through promoting various formal/informal learning opportunities.

- Providing opportunities for the targeted employees to work with the IT through their participation and empowerment in the IT project once the technology is introduced.

Based on evidence from three exploratory case studies, we compiled a list of 17 HRM practices that could contribute to an HRM system oriented towards reinforcing the desired user behaviour in IT implementation projects, and hence likely to ensure IT implementation success.

\footnotetext{
${ }^{1}$ The authors are thankful to the anonymous reviewer for these suggestions.
}

\section{Appendix}

Interview protocol "HRM systems for IT implementations"

\section{Basic information}

- Function (official title)

- Educational background

- Job tasks, activities and responsibilities

- Experience working for the company

- Experience working for this department

- Experience with operating software

\section{HRM system}

- Who initiated the introduction of IT?

- Did you participate in the decision-making during the introduction of the system? How?

- During 'getting used' to the system - what kind of responsibilities did you have? Did you have the authority to make decisions concerning use of the system? Please specify

- Was it possible to create your own style of working with the system?

- Did you have enough authority to plan your own work?

- Did you have enough time to experiment, discuss and try out the system?

- What were/are the educational / training possibilities to learn about the system (training sessions, informal learning, consultations, materials)?

- Which of them were the most helpful? Why?

- Were your efforts to get used to the system recognised/ noticed/ paid attention to? In what ways? And now?

- Was there a special system of rewards for using the IT?

- Did you get helpful comments on the mistakes from the managers?

- Was your gradual progress recognised? How?

- Were you rewarded for your efforts? How?

- What kind of help did /do you get from the managers concerning use of the system? In what ways do you cooperate with them?

- Did the managers allocate enough time to support you in getting used to the system?

\section{References}

Agarwal, R. and Karahanna, E. (2000) Time flies when you're having fun: Cognitive absorption and beliefs about information technology usage. MIS Quarterly 24(4), 665-694.

Ambrose, P. J., Ramaprasad, A. and Rai, A. (1998) Information Systems, Knowledge Work and the IS Professional: Implications for Human Resource Management. CPR-98. ACM Publications, Boston, MA, USA, pp. 78-81.

Badham, R., Garrety, K. and Kirsch, C. (2001) Humanistic redesign and technological politics in organisations. Journal of Organisational Change 14(1), 50-63.

Becker, B. E. and Gerhart, B. (1996) The impact of human resource management on organizational performance: Progress and prospects. Academy of Management Journal 39, 779-801.

Benbasat, I. and Taylor, R. N. (1978) The impact of cognitive styles on information systems design. MIS Quarterly 2(2), 43-54. 
Bloomfield, B. P., Coombs, R., Cooper, D. J. and Rea, D. (1992) Machines and manoeuvres: Responsibility accounting and the construction of hospital information systems. Accounting, Management \& Information Technology 2(4), 197-219.

Bondarouk, T. (2006) Action-oriented group learning in the implementation of information systems: Results from three case studies. European Journal of Information Systems 15(1), 42-53.

Bondarouk, T. and Looise, J. C. (2005) HR contribution to IT innovation implementation: Results of three case studies. Creativity and Innovation Management 14(2), 160-169.

Bondarouk, T. and Sikkel, K. (2005) Explaining IT implementation through group learning. Information Resource Management Journal 18(1), 364-381.

Bondarouk, T. and Van Riemsdijk, M. (2007) Successes and failures of SAP implementation: A Learning perspective. International Journal of Technology and Human Interactions 3(4), 33-52.

Brancheau, J. C., Janz, B. D. and Wetherbe, J. C. (1996) Key issues in information systems management: 1994-05 SIM Delphi results. MIS Quarterly/ June, 225-242.

Chung, C. A. (1997) Human issues influencing the successful implementation of advanced manufacturing technology. Journal of Engineering and Technology Management 13, 283-299.

Ciborra, C. U. (1999) A theory of information systems based on improvisation. In Rethinking management information systems, (eds) W. L. Currie and B. Galliers, pp. 136-157. Oxford University Press.

Claver, E., Gonzales, R. and Llopis, J. (2000) An analysis of research in information systems $(1981$ - 1997). Information \& Management 37, 181-195.

Cooper, R. G. (1999) From experience: Ihe Invisible success factors in product innovation. Journal of Product Innovation Management 16, 115-133.

Davis, Fred (1989) Perceived usefulness, perceived ease of use, and user acceptance of information technology. MIS Quarterly 13, 319-339.

Dawson, P., Clause, C. and Nielsen, K. (2000) Political processes in management, organization and the social shaping of technology. Technology Analysis \& Strategic Management 12(1), 5-15.

Doll, W. J. and Torkzadeh, G. (1990) The measurement of end-user software involvement. OMEGA 18(4), 399-406.

Fehse, K.I.A. (2002). The role of organisational politics in the implementation of information systems. Three cases in a hospital context. PhD thesis, Enschede, The Netherlands.

Ferrat, T. W., Agarwal, R., Brown, C. V. and Moore, J. E. (2005) IT Human Resource Management configurations and IT turnover: Theoretical synthesis and empirical analysis. Information Systems Research 16(3), 237-255.

Fleischer, M., Liker, J. and Arnsdorf, D. (1987) Effective use of computer-aided design and computer-aided engineering in manufacturing. Industrial Technology Institute, Ann Arbor, Ml.

Jarvenpaa, S. L. and Leidner, D. E. (1998) An information company in Mexico: Extending teh Resource-based view of the firm to a developing country context. Information Systems Research 9(4), 342-361.

Jordan, E., \& Whiteley, A.M. (1994). HRM practices in information technology management. SIGCPR-94, March 1994, (pp. 57-64), Alexandria, Virginia, USA.

Karahanna, E., Agarwal, R. and Angst, C. M. (2006) Reconceptualizing compatibility beliefs in Technology Acceptance research. MIS Quarterly 30(4), 781-804.

King, W. R. and He, J. (2006) A meta-analysis of the technology acceptance model. Information \& Management 43, 740-755.

Klein, K. J. and Ralls, R. S. (1997) The unintended organisational consequences of technology training: implications for training theory, research, and practice. In Improving Training Effectiveness in Organizations, (eds) J. K. Ford, S. Kozlowski, E. Salas and M. Teachout, pp. 323-354. Erlbaum, Hillsdale, NJ.
Klein, K. J. and Sorra, J. S. (1996) The challenge of innovation implementation. Academy of Management Review 21, $1055-1080$.

Klein, K. J., Conn, A. B. and Sorra, J. S. (2001) Implementing computerized technology: An Organizational analysis. Journal of Applied Psychology 86(5), 811-824.

Kuruppuarachchi, P. R., Mandal, P. and Smith, R. (2002) IT project implementation strategies for effective changes: A Critical review. Logistics Information Management 15(2), 126-137.

Leidner, D. E. and Kayworth, T. (2006) A review of culture in information systems research: Toward a theory of information technology culture conflict. MIS Quarterly 30(2), 357-399.

Lepak, D. P., Hui, L., Chung, Y. and Harden, E. (2006) A conceptual review of Human Resource Management systems in strategic human resource management research. Research in Personnel and Human Resource Management 25, 217-271.

Lepak, D. P., Marrone, J. A. and Takeuchi, R. (2004) The relativity of HR systems: Conceptualizing the impact of desired employee contributions and HR philosophy. International Journal of Technology and Management 27(6/7), 639-655.

Lu, H. P., Yu, H. Y. and Lu, S. S. K. (2001) The effects of cognitive style and model type on DSS acceptance: An Empirical study. European Journal of Operational Research 131, 649-663.

Marler, J. H., Liang, X. and Dulebohn, J. H. (2006) Training and effective employee information technology use. Journal of Management 32(5), 721-743.

Martinez, E. (1994) Avoiding large-scale information systems project failure: The Importance of fundamentals. Project Management Journal 25(2), 17-25.

McLoughlin, I., Badham, R. and Couchman, P. (2000) Rethinking political process in technological change: socio-technical configurations and frames. Technology \& Strategic Management 12(1), 17-37.

Meyers, P. W., Sivakumar, K. and Nakata, C. (1999) Implementation of industrial process innovations: factors, effects, and marketing. Journal of Product Innovation Management 16, 295-311.

Mumford, M. (2000) Managing creative people: strategies and tactics for innovation. Human Resource Managemnt Review 10(3), 313-351.

Niederman, F. and Mandviwalla, M. (2004) Introduction to special issue on the evolution of IT (computer) personnel research: More theory, more understanding, more questions. The DATA BASE for Advances in Information Systems 35, 6-8.

Orlikowski, W. (1992) The duality of technology: Rethinking the concept of technology in organizations. Organisation Science 3(3), 398-427.

Pavlou, P. A. and Fygenson, M. (2006) Understanding and predicting electronic commerce adoption: an extension of the theory of planned behavior. MIS Quarterly 30(1), 115-143.

Pinto, J. K. (1998) Project management handbook. (first ed.). Jossey-Bass, San Francisco, CA.

Rivard, S. (1987) Successful implementation of end-user computing. Interfaces 17(3), 25-33.

Robey, D., Boudreau, M.-C. and Rose, G. M. (2000) Information technology and organisational learning: A Review and assessment of research. Accounting Management and Information Technologies 10, 125-155.

Rousseau, D. M. (1989) Managing the change to an automated office: Lessons from five case studies. Office: Technology and People 4, 31-52.

Ruël, H. J. M. (2001) The non-technical side of office technology; Managing the clarity of the spirit and the appropriation of office technology. Twente University Press, The Netherlands.

Schell, G. P. (1998) Perspectives on computer personnel research. Computer Personnel, 3-12.

Schuler, R. (1992) Strategic human resource management: Linking the people with the strategic needs of the business. Organizational Dynamics 21, 18-32. 
Snitkin, S. R. and King, W. R. (1986) Determinants of the effectiveness of personal decision support systems. Information \& Management 10(2), 83-89.

Taylor, W. A. (2004) Computer-mediated knowledge sharing and individual user differences: An exploratory study. European Journal of Information Systems 13, 52-64.

Tomlin, R. (1991) Developing a management climate culture in which information technology will flourish: How the UK can benefit. Journal of Information Technology 6, 45-55.

Vadapalli, A. and Mone, M. A. (2000) Information technology project outcomes: User participation structures and the impact of organization behavior and human resource management issues. Journal of Engineering and Technology Management 17, 127-151.

Venkatesh, V. (2000) Determinants of perceived ease of use: Integrating control, intrinsic motivation, and emotion into the technology acceptance model. Information Systems Research 11(4), 342-366.

Zuboff, S. (1988) In the age of the smart machine: the future of work and power. Basic Books, New York.

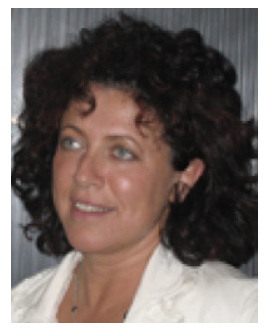

TANYA BONDAROUK is an Assistant Professor in Human Resource Management at the University of Twente, the Netherlands. She holds PhDs in Didactics and Business Administration. Her main publications concern the social aspects of Information Technology implementations and their connection with Human Resource Management and the Management of IT. Her research covers both private and public sectors and deals with a variety of areas such as the management of IT change, HRM contribution to IT projects, organisational discourse and IT implementation.

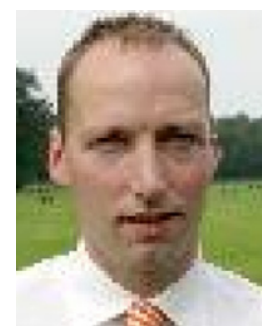

HUUB RUËL works as an Assistant Professor of International Management at the University of Twente, before that - at the KuwaitMaastricht Business School (Kuwait), and the University of Utrecht (The Netherlands). He holds a PhD in Business Administration/ Human Resource Management. His thesis focused on implementation of IT's in officeenvironments. After that his main research focus became e-HRM, combining his IT and HRM knowledge. In 2004 he published a book e-HRM: innovation or irration? together with dr. Tanya Bondarouk, in which the results of e-HRM implementation in five large international companies were described. Articles derived from this e-HRM study have been published in academic and professional journals. 